\title{
ASD device closure in elderly adults
}

\author{
Chandra Mani Adhikari', Sachin Dhungel ${ }^{2}$, Amrit Bogati ${ }^{3}$, Jagat Adhikari ${ }^{4}$, \\ Manish Shrestha ${ }^{5}$, Kiran Prasad Acharya ${ }^{6}$
}

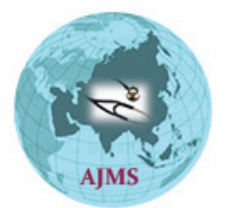

${ }^{1}$ Cardiologist, Department of Cardiology, Shahid Gangalal National Heart Centre, Nepal, Associate Professor, National Academy of Medical Sciences, Kathmandu, Nepal, ${ }^{2,3}$ Registrar, Department of Cardiology, Shahid Gangalal National Heart Centre, Nepal, ${ }^{4,6}$ Resident, Department of Cardiology, Shahid Gangalal National Heart Centre, Nepal, ${ }^{5}$ Pediatric Cardiologist, Shahid Gangalal National Heart Centre, Nepal

\section{A B S T R A C T}

Background: Closure of ASDs in elderly patients caused significant clinical and hemodynamic improvement after device closure. Aims and Objective: We aim to share our experience of ASD device closure in elderly adults. Materials and Methods: It was a prospective single center study done at Shahid Gangalal National Heart Centre. All elderly patients (>50years) who underwent ASD device closure fromFeb 2016 to July 2018 and completed three months of device closure were prospectively follow up for the symptoms, RA and RV dimension, Tricuspid Regurgitation and Tricuspid Regurgitation pressure gradient (TRPG). Results: During the study period 48 elderly adults underwent successful ASD device closure. Except one patient we could follow up all patients. Among the patient's 33 were female, Age ranged from $50 y e a r s$ to 72 years with the mean age of 55 years. Shortness of breath was the most common symptom during presentation. ASD size ranged from $10 \mathrm{~mm}$ to $33 \mathrm{~mm}$ with the mean of $23 \mathrm{~mm}$. Device size ranged from $14 \mathrm{~mm}$ to $40 \mathrm{~mm}$ with the mean of $29 \mathrm{~mm}$. Amplatzer septal occluder was used in 47 patients. RA and RV were dilated in all patients. Mild TR was present in 26 patients, Moderate TR in 17 patients, Severe TR in 5 patients. Mean follow-up time was 12 months. Symptoms reduced in all patients expect one. RA and RV size reduced in all patients. Tricuspid regurgitation pressure gradient reduced from mean of $56 \mathrm{mmHg}$ to Mean of $16 \mathrm{mmHg}$. During the follow up level of tricuspid regurgitation reduced, 11 patients had mild TR, Trace TR in 15 patients. Conclusion: ASD device closure can result in improvement in clinical and hemodynamic in elderly adults.

Access this article online

Website:

http://nepjol.info/index.php/AJMS DOI: 10.3126/ajms.v10i3.23195 E-ISSN: 2091-0576 P-ISSN: 2467-9100

Key words: ASD; Trans catheter closure; Amplatzer Septaloccluder

\section{INTRODUCTION}

Closure of an ASD in patients with a hemodynamically significant shunt has become the standard of care in recent years. Correction of ASDs prevents the development of pulmonary hypertension, cardiac arrhythmia, and heart failure. ${ }^{1,2}$ Closure of ASDs in elderly patients remains controversial. ${ }^{3}$ The aim of this study is to evaluate the outcomes of transcatheter closure of secundum ASDs in elderly patients.

\section{MATERIALS AND METHOD}

It was a prospective single center study done at Shahid Gangalal National Heart Centre. All elderly patients (>50years) who underwent ASD from 2016 Feb to July 2018 and completed three months of device closure were prospectively follow up about the symptom, Right atrium and Right ventricle size, tricuspid regurgitation (TR) and tricuspid regurgitation pressure gradient (TRPG).Patient's co-morbid condition was also recorded. Catheterization laboratory record were reviewed for the ASD size, device size any complications. Hospital record book were reviewed for any in-hospital complications. Patientsymptoms, Right atrium and Right ventricle size, TR and TRPG before and after the device closure were compared. This study was approved by the institutional review committee of Shahid Gangalal National Heart Center.

\section{RESULTS}

During the study period 425 patients underwent successful device closure in the Shahid Gangalal National Heart 
Centre. Among them 48were elderly adults ( $\geq 5$ yyears) underwent successful ASD device closure. Expect one patient all could befollowed up. Among the patient's 33 were female, Age ranged from 50years to 72years with the mean age of 55 years. Shortness of breath was the most common symptom before device closure followed by chest pain. ASD size ranged from $10 \mathrm{~mm}$ to $33 \mathrm{~mm}$ with the mean of $23 \mathrm{~mm}$. Device size ranged from $14 \mathrm{~mm}$ to $40 \mathrm{~mm}$ with the mean of $29 \mathrm{~mm}$. Amplatzer septaloccluder was used in 47 patients with Amplatazer septal occluder was used in 47 patients as shown in Table 1. One patient underwent ASD device closure with memo part ASD device. Except one patient all patient underwent ASD device closure under local anesthesia with transthoracic echocardiogram guidance. RA and RV were dilated in all patients. Mild TR was present in 26 patients, Moderate TR in 17 patients, Severe TR in 5 patients. Sinus rhythm was present in 47 patients, RBBB was present in 44 patients, and one patient had LBBB in ECG. Two patients had coronary artery disease, two had chronic obstructive pulmonary disease (COPD), three had hypertension and two had diabetes mellitus. One patient underwent PCI of RCA during the device closure. One patient had history of Coronary artery bypass graft (CABG). During the procedure one patient had pseudo aneurysm which required surgical repair. One patient developed pneumonia and in one patient device embolized but underwent device closure with another device. Mean follow-up time was 12 months. Symptoms reduced in all patients expect one. RA and RV size reduced in all patients. Pulmonary artery reduced from mean of $56 \mathrm{mmHg}$ to Mean of $16 \mathrm{mmHg}$. During the follow up level of tricuspid regurgitation reduced, 11patients had mild TR, Trace TR in 15 patients as shown in Table 2.

\section{DISCUSSION}

The benefits from ASD closure in the elderly population has been documented in fewer reports compared to the younger population. Recent randomized study in a large population confirmed that anatomical closure is superior to medical treatment in preventing major events. ${ }^{4}$ Moreover, the realistic benefits of ASD closure include symptomatic relief, improvements of functional status as well as the quality of life. ${ }^{5,6}$ These favorable clinical changes are supported by the immediate and substantial reverse remodeling of the heart after closure from many studies. ${ }^{7-11}$

Our study showed that ASD device closure in elderly is safe. ASD device closure can decrease in symptom. Decrease in symptom (breathlessness and palpitation) and improved functional class after device closure was observed in many studies. ${ }^{3,12-15}$ Khan et al. reported that significant improvement in functional class and echocardiographic

\begin{tabular}{|c|c|}
\hline $\begin{array}{l}\text { Clinical } \\
\text { characteristics }\end{array}$ & $n(\%)$ \\
\hline Male & $15(31.2 \%)$ \\
\hline Female & $33(68.8 \%)$ \\
\hline Mean age & $55.6 \pm 4.6$ years \\
\hline Age range & $50-72$ years \\
\hline ASD size & Mean $23.0 \pm 6.0 \mathrm{~mm}$ (10 to 33$)$ \\
\hline ASD device size & Mean $29.8 \pm 6.7 \mathrm{~mm}$ (14 to 40$)$ \\
\hline ASD device type & $\begin{array}{l}\text { Amplatzer } 47(97.9 \%) \text {, Memo } \\
\text { part } 1(2.1 \%)\end{array}$ \\
\hline Follow up & $47(97.9 \%)$ patients \\
\hline Lost follow up & One $(2.1 \%)$ patient \\
\hline Mean Follow up time & 12 months \\
\hline Comorbid issues & $\begin{array}{l}\text { Coronary artery disease } 2(5.5 \%), \\
\text { Diabetes } 1(2.1 \%) \\
\text { Hypertension } 2(4.1 \%), \text { COPD } 2(4.1 \%) \\
\text { One }(2.1 \%) \text { underwent PCl } \\
\text { One }(2.1 \%) \text { had undergone CABG }\end{array}$ \\
\hline Complications & $\begin{array}{l}\text { Device embolization } 1(2.1 \%) \\
\text { Groin Hematoma } 1(2.1 \%)\end{array}$ \\
\hline
\end{tabular}

\begin{tabular}{|c|c|c|}
\hline $\begin{array}{l}\text { Clinical } \\
\text { characteristics }\end{array}$ & $\begin{array}{l}\text { Before device } \\
\text { closure }\end{array}$ & $\begin{array}{l}\text { After device } \\
\text { closure }\end{array}$ \\
\hline \multicolumn{3}{|l|}{ Symptoms } \\
\hline Dyspnea & $47(100 \%)$ & $\begin{array}{l}\text { Improved } \\
46(97.8 \%)\end{array}$ \\
\hline Palpitation & $7(16.5 \%)$ & Improved $7(100 \%)$ \\
\hline Chest pain & $12(27.7 \%)$ & Improved $12(100 \%)$ \\
\hline \multicolumn{3}{|l|}{ ECG } \\
\hline RBBB & $44(93.6 \%)$ & $44(93.6 \%)$ \\
\hline LBBB & $1(2.1 \%)$ & $1(2.1 \%)$ \\
\hline \multicolumn{3}{|l|}{ Echocardiography } \\
\hline Dilated RA & $47(100 \%)$ & 0 \\
\hline Dilated RV & $47(100 \%)$ & 0 \\
\hline \multicolumn{3}{|c|}{ Tricuspid regurgitation } \\
\hline Nil & $0(0 \%)$ & $21(44.6 \%)$ \\
\hline Trace & $1(2.1 \%)$ & 15 (31.9\%) \\
\hline Mild & $25(53.1 \%)$ & $11(23.4 \%)$ \\
\hline Moderate & $16(34.1 \%)$ & 0 \\
\hline Severe & $5(10.6 \%)$ & 0 \\
\hline TRPG $(\mathrm{mmHg})$ & $56.9 \pm 19.2$ & $16.1 \pm 13.2$ \\
\hline
\end{tabular}

parameters as early as 6 weeks post device closure. There was correlation of functional class and 6 -min walk test. ${ }^{15}$ In a study done Among middle-aged adults $(\geq 40$ years old), ASD closure has been shown to improve functional capacity, right ventricular chamber dimensions, heart failure progression, and overall survival. ${ }^{16-18} \mathrm{In}$ a study in patients above age 60 showed, ASD device closure in the elderly improved functional capacity, with a decrease, but not a normalization of RV dimensions and PASP, and an increase in LV dimensions, EF and mitral E/A-ratio. ${ }^{19}$

In our study we noticed that normalization of RA and RV size and decrease in pulmonary artery pressure significant after the device closure. Right ventricular dilation reduction has been found to decrease overall after closure. ${ }^{20}$ Ghosh et al ${ }^{21}$ also found a size reduction in RV 
in the elderly, but not as pronounced as in the young. In another study, no difference in the reduction of RV size between age groupsand that substantial RV reduction is possible even in the elderly patients. It was observed that despite longstanding RV dilation from volume overload, there is still potential for improvement in RV size and possible improvement in function even in those over 40 years. ${ }^{13}$ Altinag et al. reported $58 \%$ patients with severe RV dilatation prior to intervention had no or mild dilatation at last follow-up. Reduction of RV dilatation was not related to age. ${ }^{14}$ There was statistically highly significant reduction in Pulmonary artery pressure from the baseline. The reduction in pulmonary artery pressure was observed in multiple studies in elderly. ${ }^{13-15}$

One of the most discussed subjects regarding closing an ASD in the elderly is the impact on AF. Several studies find no or onlyvery little effect on the development of AF when treated late in life..$^{22,23}$ In a recent study on elderly patients with ASD and chronic atrial fibrillation, reported that the outcome of device closure was as good as the outcome from patients without atrial fibrillation in terms of safety, improvement of functional status and reverse remodeling of the heart. ${ }^{24}$

In the setting of mounting comorbid illnesses and reduced life expectancy in older patients, quality over quantity of life has been observed to have an increasingly important role. ${ }^{25}$ After device closure most elderly experience subjective improvement of symptoms. The elderly has no increased hospitalization, complications or mortality compared with the young. Elderly patients should therefore not be withheld from closure of a significant ASD. ${ }^{12}$

\section{CONCLUSION}

ASD device closure in elderly results in decrease in symptoms, improve functional class, decrease RV dilation and decrease in pulmonary pressure.

\section{REFERENCES}

1. Campbell M. Natural history of atrial septal defect. Heart 1970; 32:820-826

2. Hoffman $\mathrm{JI}$ and Kaplan S.The incidence of congenital heart disease. Journal of the American College of Cardiology 2002; 39:1890-1900.

3. Komar M, Przewlocki T, Olszowska M, Sobien B and Podolec P. The benefit of atrial septal defect closure in elderly patients. Clinical Interventions in Aging 2014; 9:1101-1107.

4. Attie F, Rosas M, Granados N, Zabal C, Buendía A and Calderón J. Surgical treatment for secundum atrial septal defects in patients $>40$ years old. Journal of the American College of Cardiology 2001; 38 (7): 2035-2042.

5. Miyaji K, Furuse A, Tanaka O, Kubota H, Ono M and Kawauchi M.
Surgical repair for atrial septal defect in patients over 70 years of age. Japanese Heart Journal 1997; 38:677-684.

6. Shibata Y, Abe T, Kuribayashi R, Sekine S, Seki K, Yamagishi I, et al. Surgical treatment of isolated secundum atrial septal defect in patients more than 50 years old. The Annals of Thoracic Surgery 1996; 62:1096-1099.

7. Spies $\mathrm{C}$ and Hijazi ZM. Transcatheter Closure of Secundum Atrial Septal Defects in the Elderly. Korean Circlation Journal 2009; 39:47-51.

8. Swan L, Varma C, Yip J, Warr M, Webb G, Benson L, et al. Transcatheter device closure of atrial septal defects in the elderly: Technical considerations and short-term outcomes. International Journal of Cardiology 2006; 107:207-210.

9. Elshershari H, Cao QL and Hijazi ZM. Transcatheter device closure of atrial septal defects in patients older than 60 years of age: immediate and follow-up results. The Journal of Invasive Cardiology 2008; 20:173-176.

10. Yalonetsky S and Lorber A. Comparative Changes of Pulmonary Artery Pressure Values and Tricuspid Valve Regurgitation Following Transcatheter Atrial Septal Defect Closure in Adults and the Elderly. Congenital Heart Disease 2009; 4:17-20.

11. Kim NK, Park SJ and Choi JY. Transcatheter Closure of Atrial Septal Defect: Does Age Matter? Korean Circulation Journal 2011; 41:633-638.

12. Camilla N, Morten FG, Jens ENK and Vibeke H. Closure of secundum atrial septal defects in the adult and elderly patients. European Journal of Cardio-Thoracic Surgery 2013; 43:752-757.

13. Kariyappa M, Mahimrangaiah J, Puttegowda B, Agrawal N, Shastry SL, Chikkaswamy SB, et al. Device Closure of Atrial Septal Defect in Patients of Age More than 40 Years: Immediate and Intermediate Out Come. International Journal of Scientific Study 2015;3(5):23-29.

14. Altindag JW, Roos-Hesselink JAAE, Cuypers R, van Domburg PPT, de Jaegere F, Meijboom J, et al. Transcatheter device closure of atrial septal defects in patients aged 40 years and older. Netherlands Heart Journal 2010; 18:537-542.

15. Khan AA, Tan JL, Li W, Dimopoulos K, Spence MS, Chow P, et al. The impact of transcatheter atrial septal defect closure in the older population: A prospective study. JACC: Cardiovascular Interventions 2010;3:276-281.

16. Jemielity $M$, Dyszkiewicz W, Paluszkiewicz L, Perek B, Buczkowski $P$ and Poniz yński A. Do patients over 40 years of age benefit from surgical closure of atrial septal defects? Heart 2001; 85:300-303.

17. Konstantinides S, Geibel A, Olschewski M, Görnandt L, Roskamm H, Spillner G, et al. A comparison of surgical and medical therapy for atrial septal defect in adults. New England Journal of Medicine 1995; 333:469-473.

18. Attie F, Rosas M, Granados N, Zabal C, Buendía A and Calderón J. Surgical treatment for secundum atrial septal defects in patients 40 years old. A randomized clinical trial. Journal of the American College of Cardiology 2001; 38: 2035-2042.

19. Ströker E, Bruaene AVD, Meester PD, Deyck KV, Gewillig M and Budts W. Transcatheter device closure of atrial septal defects in patients above age 60. Journal Acta Cardiologica 2013; 68:127-132.

20. Veldtman GR, Razack Z, Siu S, El-Hajj H, Walker F, Webb GD, et al. Right ventricular form and function after percutaneous atrial septal defect device closure. Journal of the American College of Cardiology 2001; 37:2108-2113.

21. Ghosh S, Chatterjee S, Black E and Firmin RK. Surgical closure of atrial septal defects in adults: effect of age at operation on outcome. Heart 2002; 88:485-487.

22. Patel A, Lopez K, Banerjee A, Joseph A, Cao QL and Hijazi ZM. Transcatheter closure of atrial septal defects in adults 40 years 
of age: immediate and follow-up results. Journal of Interventional Cardiology 2007; 20:82-88.

23. Silversides CK, Siu SC, McLaughlin PR, Haberer KL, Webb GD, Benson L, et al. Symptomatic atrial arrhythmias and transcatheter closure of atrial septal defects in adult patients. Heart 2004; 90:1194-1198.
24. Taniguchi M, Akagi T, Ohtsuki S, Okamoto $\mathrm{Y}$, Tanabe $\mathrm{Y}$, Watanabe N, et al. Transcatheter closure of atrial septal defect in elderly patients with permanent atrial fibrillation. Catheterization Cardiovascular Interventions 2009; 73:682-686.

25. Tsevat J, Dawson NV, Wu AW, Lynn J, Soukup JR, Cook EF, et al. Health values of hospitalized patients 80 years or older. JAMA 1998; 279:371-375

\section{Authors Contribution:}

CMA- Concept and design of the study, manuscript preparation, statistically analyzed and interpreted, Critical revision of the manuscript; SD- Concept and design of the study, critical revision of manuscript and review of the study; AB- reviewed the literature, helped in preparing first draft of manuscript, collected data; JA-collected data, statistically analyzed and interpreted, helped in preparing first draft of manuscript; MS- reviewed the literature, helped in preparing first draft of manuscript; KPA- collected data, statistically analyzed and interpreted, helped in preparing first draft of manuscript.

\section{Work attributed to:}

Department of Cardiology, Shahid Gangalal National Heart Centre, Kathmandu, Nepal

Orcid ID:

Dr. Chandra Mani Adhikari- (10) https://orcid.org/0000-0001-5811-9977

Dr. Kiran Prasad Acharya- (D https://orcid.org/0000-0003-2765-4242

Source of Support: Nil, Conflict of Interest: None. 